\title{
MAGNITUDE AND CAUSES OF VISUAL IMPAIRMENT AND BLINDNESS AMONG CHILDREN ATTENDING PAEDIATRIC EYE CLINIC AT SANTHIRAM MEDICAL COLLEGE
}

\author{
P. Sanjeeva Kumar', M. Ramesh Chandra², P. Kishore Kumar ${ }^{3}$, P. Sai ${ }^{4}$ \\ ${ }^{1}$ Assistant Professor, Department of Ophthalmology, Santhi Ram Medical College \& General Hospital. \\ ${ }^{2}$ Assistant Professor, Department of Ophthalmology, Santhi Ram Medical College \& General Hospital. \\ ${ }^{3}$ Assistant Professor, Department of Ophthalmology, Santhi Ram Medical College \& General Hospital. \\ ${ }^{4}$ Senior Resident, Department of Ophthalmology, Santhi Ram Medical College \& General Hospital.
}

\section{ABSTRACT}

\section{BACKGROUND}

The number of blind years resulting from blindness in children is alarmingly high. Blindness in children can have a significa nt impact on their performance at school as well as their social interaction and future employment as visually impaired children have a long lifetime of blindness ahead of them. The consequences of visual impairment and blindness in children are an important public health issues with greater impact in developing countries, where $80 \%$ of the blindness in children occurs. The control of blindness in children is considered a high priority area within the World Health Organization's VISION 2020 initiative. However many developing countries do not have the accurate information about the magnitude and causes of visual impairment and blindness in children, from which the scope and priorities for prevention and treatment can be identified. To date the established Pediatric Eye Clinic, which works as a Tertiary Eye Centre does not have baseline data on the magnitude and causes of visual impairment and blindness in children.

\section{KEYWORDS}

Birth Asphykia Cortical Blindness Opthalmia Neonatarum

HOW TO CITE THIS ARTICLE: Kumar PS, Chandra MR, Kumar PK, et al. Magnitude and Causes of Visual Impairment and Blindness Among Children Attending Paediatric Eye Clinic at Santhiram Medical College. J. Evolution Med. Dent. Sci. 2016;5(13):593-596, DOI: $10.14260 /$ jemds/2016/135

\section{INTRODUCTION LITERATURE REVIEW PREVALENCE}

A recent estimation by the World Health Organization (WHO) suggests that about 161 million people in the world have visual impairment and among them 45 million are blind. Among the blind people, 1.4 million are children below 16 years of age. ${ }^{1,2}$ The prevalence of childhood blindness worldwide is estimated to be around $0.07 \%$ and it is estimated to be about one-tenth that of adults. ${ }^{3}$ However, a blind child suffers from more blind years than adults.

The magnitude varies from country to country and from place to place within one country. ${ }^{4}$ Majority of blind children are estimated to live in developing world and Africa in particular, as it was estimated that only $6.5 \%$ of the blind children live in the developed countries. ${ }^{5}$ Approximately, three-quarters of the blind children in the world live in the poorest regions of Africa and Asia. ${ }^{6}$ The available data suggests that there may be a ten-fold difference in prevalence between the developed countries of the world and the poorest ranging from 0.3 per 1000 children in wealthiest countries to 1.5 per 1000 children in the poorest countries. ${ }^{4} \mathrm{~A}$ study done in Republic of Czech among children attending school for the visually handicapped found that among 229 children aged 615 years, $20.5 \%$ had severe visual impairment while $69.5 \%$ were blind. ${ }^{7}$

Financial or Other, Competing Interest: None

Submission 19-11-2015, Peer Review 21-11-2015,

Acceptance 23-11-2015, Published 15-02-2016.

Corresponding Author:

P. Sanjeeva Kumar,

Department of Ophthalmology,

Santhi Ram Medical College \& General Hospital.

NH-18, Nandyala.

E-mail: srmcopthal@gmail.com

DOI:10.14260/jemds/2015/135

\section{PROBLEM STATEMENT}

The number of blind children is estimated to be 1.4 million worldwide with global prevalence of childhood blindness of $0.07 \%$. Approximately, three quarters of the world's blind children live in the poorest regions of Africa and Asia. ${ }^{6}$

Most of the available data on the prevalence and causes of visual impairment and blindness in children from developing countries have been obtained from examining children from schools for the blind. These data are biased as not all blind children go to these schools. 6

It is thought that only $10 \%$ of blind children in developing countries are in schools for the blind. Blind children not attending these schools are underestimated and not being represented by these data. ${ }^{6}$

The pattern of causes of visual impairment and blindness in children changes with time. The interventions for child health and survival with vitamin A supplementation and measles immunization may have an impact on the causes of blindness. Recent studies in Tanzania were done in schools for the blind. Data from these studies represent the causes 15 years ago and probably may not reflect the current situation.

\section{RATIONALE}

The study has provided baseline information on the prevalence and causes of childhood visual impairment and blindness for the clinic and the hospital. The recognition of these causes will be important for the management of patients attending the Pediatric Ophthalmology Clinic and improving their quality of life. The results will also help in planning and evaluating appropriate preventive and curative services of avoidable causes of blindness in children in the country. Many cases of visual impairment and blindness in children are reported to be avoidable, therefore having measures for their prevention and treatment will have a significant impact on reducing the problem. These data will also help on planning special education and low vision services. 


\section{OBJECTIVES \\ BROAD OBJECTIVE}

To determine the magnitude and causes of visual impairment and blindness in children attending Pediatric Eye Clinic at Santhiram Medical College.

\section{SPECIFIC OBJECTIVES}

1. To determine the magnitude of visual impairment and blindness among children attending Pediatric Eye Clinic at Santhiram Medical College.

2. To describe the age and sex distribution of visual impairment and blindness in children attending Pediatric Eye Clinic at Santhiram Medical College.

3. To determine the causes of unilateral and bilateral visual impairment and blindness in children attending Paediatric Eye Clinic at Santhiram Medical College.

\section{METHODOLOGY}

\section{STUDY DESIGN}

A hospital based cross-sectional descriptive study.

\section{STUDY AREA}

The study was conducted at Pediatric Eye Clinic in Santhiram Medical College in Nandyal.

Pediatric Eye Clinic is part of the Ophthalmology Department of Santhiram Medical College. The clinic provides Tertiary Childhood Eye Services to a catchment population of more than 10 million in the regions of Nandyal and all children referred from other regions of Tanzania.

\section{STUDY POPULATION}

All children aged 0-16 years attending Pediatric Eye Clinic, Santhiram Medical College Hospital during the study period June-December 2010.

\section{Inclusion Criteria}

All patients with eye problems attending Paediatric Eye Clinic at Santhiram Medical College Hospital during the study period.

\section{Exclusion Criteria}

Children that have failed to take the visual acuity were excluded from the study.

\section{Sampling and Sample Size}

Convenient sampling was used. All children 0-16 years old attending Pediatric Eye Clinic, Santhiram Medical College and Hospital during the study period were included.

\section{Procedures}

All parents/guardians with children aged 0-16 years attending Pediatric Eye Clinic during the study were informed about the study. An informed consent was filled by each parents/guardian before the patient was included in the study. A thorough history was taken from parents/guardian. This was followed by a general and systemic examination, which was performed by the investigator. All information was recorded on a structured questionnaire.

Ocular examination was performed starting with visual acuity using different methods (Snellen chart, Cardiff cards and $\mathrm{K}$ pictures) according to the age and intellect of the child. Fixation and the ability to follow light in children less than one year were tested by using a pen torch. Cardiff cards, K pictures or Sheridan Gardner Singles/linear were used to assess visual acuity in children aged 2 and 3 years old respectively. For those who are literate and 4 years old Snellen chart was used. The corrected visual acuity of $6 / 4-6 / 18$ was graded as normal, that of $<6 / 18$ to $\geq 3 / 60$ was graded as visual impairment and visual acuity of less than $3 / 60$ was regarded as blind. Squint assessment was done to determine the type and angle of deviation.

Topcon slit lamp bio-microscope was used for examination of the anterior segment of the eye including the eyelids, conjunctiva, cornea, anterior chamber, iris, pupil, lens and anterior vitreous.

Intraocular pressure measurement was done using Kowa perkins tonometer in suspected cases of glaucoma. A Heine indirect ophthalmoscope was used to examine the posterior segment after dilatation of both pupils using cyclopentolate eye drops $1 \%$. Refraction was done.

\section{ETHICAL CONSIDERATION}

The study was conducted after getting permission from the ethical committee of MUHAS and according to the Helsinki declaration of 1964, in which the patient will be protected. A written informed consent was signed by those parents or guardians who accepted their children to participate in the study. All children were evaluated by the ophthalmologist and if needed by the pediatrician and were treated accordingly.

\section{Data Management and Analysis}

All questionnaires were checked daily by the investigator for information gaps, which were corrected by re-interviewing the parent/guardian. Data entry in the computer was done by Epi Info programme and data analysis was done using SPPS software.

\section{DEFINITION OF TERMS}

Visual impairment is defined as presenting visual acuity of $<6 / 18$ to $\geq 3 / 60$ in the better eye with best correction by WHO. Blindnessis defined as presenting visual acuity of less than $3 / 60$ in the better eye with best correction by WHO.

Unilateral blindness was defined as presenting visual acuity of less than 3/60 in one eye with the best correction. Children are individuals less than 16 years of age.

\section{RESULTS}

Two hundred and thirty two children were recruited and all were included in the analysis. The age range was $0-15$ years with mean age of 6.5 years. There were $133(57.3 \%)$ males. The visual acuity of 201 children was assessed by quantitative methods, while that of 31 children was assessed by light fixing and following method.

\begin{tabular}{|c|c|c|c|}
\hline $\begin{array}{c}\text { Age Group } \\
\text { (Years) }\end{array}$ & Male N (\%) & $\begin{array}{c}\text { Female N } \\
\text { (\%) }\end{array}$ & Total N (\%) \\
\hline $0-4$ & $59(60.2)$ & $39(39.8)$ & $98(42.2)$ \\
\hline $5-9$ & $35(55.6)$ & $28(44.4)$ & $63(27.2)$ \\
\hline $10+$ & $39(54.9)$ & $32(45.1)$ & $71(30.6)$ \\
\hline Total & $133(57.3)$ & $99(42.7)$ & $232(100)$ \\
\hline \multicolumn{3}{|c|}{ Table 1: Distribution of the Study } \\
Population by Age and Sex (N = 232) \\
\hline
\end{tabular}

There were $133(57.3 \%)$ males. Ninety eight $(42.2 \%)$ of the children were in the age group less than 4 years. 


\begin{tabular}{|c|c|c|c|}
\hline Visual Acuity Group & Male N & Female N & Total N \\
\hline Normal (6/4-6/18) & $102(57.6)$ & $75(42.4)$ & $177(88.0)$ \\
\hline $\begin{array}{c}\text { Visual impairment } \\
(<6 / 18-3 / 60)\end{array}$ & $10(62.5)$ & $6(37.5)$ & $16(8.0)$ \\
\hline Blindness $(<3 / 60)$ & $4(50.0)$ & $4(50.0)$ & $8(4.0)$ \\
\hline Total & $\mathbf{1 1 6}$ & $\mathbf{8 5}$ & $\mathbf{2 0 1 ( 1 0 0 )}$ \\
\hline \multicolumn{3}{|c|}{ Table 2: The Visual Acuity of 201 Children } \\
According to WHOClassification \\
\hline
\end{tabular}

Among the 201 children, 177(88.0\%) had normal vision while 8(4.0\%) were blind. (Table 2).

\begin{tabular}{|c|c|c|}
\hline Visual Acuity Group & $\mathrm{N}$ & $\%$ \\
\hline Normal $(6 / 4-6 / 18)$ & 302 & 75.1 \\
\hline Visual impairment $(<6 / 18-3 / 60)$ & 51 & 12.7 \\
\hline Blindness $(<3 / 60)$ & 49 & 12.2 \\
\hline Total & 402 & 100.0 \\
\hline
\end{tabular}

Among the 402 eyes, 302(75.1\%) had normal vision, while $49(12.2 \%)$ eyes were blind.

There were 33(16.4\%) right eyes which were blind compared to $16(8.0 \%)$ blind left eyes. (Table 3 ).

\section{DISCUSSION}

Though the magnitude of childhood blindness varies from country to country and from place to place within one country, the prevalence worldwide has been estimated to be around $0.07 \% .^{8}$ the current study has revealed a high prevalence of $4 \%$. This seems to be even higher than the prevalances reported by other studies done in other developing countries like China. ${ }^{9}$ Mongolia. ${ }^{10}$ and Southern India. ${ }^{11}$ This can be explained by the fact that the current study was a hospital based, whereas the other studies were community based.

Previous reports from Tanzania, Nigeria. ${ }^{12}$ and Ethiopia. 13 found out that corneal scars and phthisis bulbi respectively were the commonest causes of childhood blindness. Other studies from Sub-Saharan Africa reported ophthalmia neonatorum, ocular trauma, uncorrected refractive error, congenital glaucoma, corneal scarring, measles/Vitamin A deficiency, congenital cataract and genetic eye diseases to be among the commonest causes of childhood blindness. ${ }^{4,6}$ The current study found out that cortical blindness related to birth asphyxia being the commonest cause of bilateral blindness accounting for $50.0 \%$ of all the blind children. Cortical blindness was again the main cause among the eyes, which were not able to fixate and follow light. Birth asphyxia being the commonest cause of bilateral blindness may be a sign of improved neonatal care, which has led to improved survival of the babies with birth asphyxia. On the other hand, it could be a sign of poor obstetric care.

Corneal scarring due to measles and vitamin A deficiency were not the causes of blindness among children attending the clinic during the study period, although it has been known to be the commonest cause of blindness in children.14,12 This could be explained by the successful immunization coverage of measles, which has been over $80 \%$ for the last one decade. Moreover vitamin A supplementation has been incorporated into the Expanded Programme on Immunization, hence its low occurrence as a cause of childhood blindness for the moment.

\section{CONCLUSION}

Visual impairment and blindness in children is high among the children attending the Pediatric Eye Clinic in Muhimbili National Hospital with younger children being more affected with blindness than the older ones. Most of the causes of visual impairment and blindness seen were cortical blindness, ocular trauma, amblyopia due to congenital cataract, congenital glaucoma, optic neuropathy and refractive errors. These causes are either preventable or treatable. Increasing community awareness, early identification and referral and prompt treatment may lead to substantial reduction of the problem. This baseline data will guide towards putting forward strategies on prevention of ocular trauma and on improving antenatal, natal and postnatal care in order to reduce cases of cortical blindness as a cause of bilateral blindness.

\section{RECOMMENDATIONS}

1. Efforts towards prevention of ocular trauma among children should be emphasized.

2. The antenatal and natal care should be improved in order to reduce birth asphyxia and consequently cortical blindness.

3. Programmes at the community level for early identification of ocular problems in children and referral should be given priority.

\section{STUDY LIMITATIONS}

Being a hospital based study at a referral hospital in Tanzania, highly selected group of patient was studied, hence results from this study may not reflect the situation in the community.

The study was limited by small sample size, as the prevalence of blindness in children is usually too low, thus necessitating large sample size for meaningful analysis. However, the causes of blindness and low vision are unlikely to be affected by this limitation.

\section{REFERENCES}

1. World Health Organization. Preventing blindness in children. Report of a WHO/IAPB scientific meeting. WHO/PBL/00.77. Geneva: WHO, 2000.

2. Shamanna BR. Muralikrishnan R. Childhood Cataract: Magnitude, Management, Economics and Impact J Comm Eye Health 2004;17(50):17-18.

3. Bowman RJ. How should blindness in children be managed? Cambridge Ophthalmological Symposium Eye (2005) 19,1037-1043.

4. Gilbert C, Anderton L, Dandona L, Foster A. Prevalence of blindness and visual impairment in children: a review of available data. Ophthalmic Epidemiol 1999 Mar;6(1):7381.

5. Fu P, Yang L, Bo SY, Na X. A national survey on low vision and blindness of 0-6 years old children in China. Zhonghua Yi XueZaZhi. 2004 Sept17;84(18):1525-8.

6. Gilbert C, Foster A. Childhood blindness in the context of Vision 2020-the right to sight. Bull World Health Organ 2001;79:227-32.

7. Dandona R, Dandona L. Childhood blindness in India: a population based perspective. Invest Ophthalmology Vis Sci 2008 0ct;49(10):4308-13.

8. Bowman RJ. How should blindness in children be managed? Cambridge Ophthalmological Symposium Eye (2005) 19, 1037-1043. 
9. Vijaya K, Peter H. Characteristics of a paediatric low vision population in a Private Eye Hospital in India. Ophthalmic and physical optics, Volume 20, issue 3, pages 212-218, May 2000.

10. Ajaiyeoba A, Isawumi M, et al. Prevalence and causes of blindness and visual impairment among children SouthWestern Nigeria. Int Ophthalmol 2005 Aug-Oct;26(45):121-5.

11. Nkanga D, Dolin P. Blindness and visual impairment in primary school children in Enungu State Nigeria. EAM J Ophthalmol 1998;75(8):478-480.
12. Kello A, Gilbert C. Causes of severe visual impairment and blindness in schools for the blind in Ethiopia. Br J Ophthalmol 2003 May;87(5):526-30.

13. Kingo A, Ndawi B. Prevalence and causes of low vision among school children in Kibaha District, Tanzania; Tanzania Journal of Health Research, Vol. 11, No. 3, July 2009; pp.111-115.

14. Silvana AS, Shane RD, Erika H, et al. Prevalence and causes of visual impairment in a Brazilian population: The Botucatu Eye Study BMC Ophthalmology 2009,9: 8doi:10.1186/1471-2415-9-8. 